individually. In the dermatological section Dr. E. G. Graham Little contributes a careful study of Granuloma Annulare, in which he groups under a single heading a series of cases which have been described under varying titles by different observers. In the laryngological section Dr. P. Watson Williams reports a remarkably successful external osteoplastic operation in a case of Malignant Growth of the Septum and Naso-pharynx. Amongst many other interesting cases may be mentioned one of hysteria with very unusual laryngeal manifestations, reported by Sir Felix Semon, and another of probable combination of laryngeal tuberculosis and syphilis by the same observer. In the medical section Dr. A. M. Gossage contributes a paper on the Tone of Cardiac Muscle, illustrated by many tracings, which embodies some original conceptions and includes observations upon dilatation, the extra-systole, and the action of digitalis. The neurological section is occupied with cases reported by Dr. H. G. Turney, Dr. G. Ogilvie, Dr. H. Campbell Thomson, Dr. Wilfred Harris, Dr. Leonard G. Guthrie, Dr. D. W. Carmalt-Jones, and others. The obstetrical and gynæcological section also contains several case reports, including one by Dr. Cuthbert Lockyer on Pregnancy in the Wall of a Tubal Sac. Dr. J. H. Teacher contributes, in conjunction with Dr. T. H. Bryce, an abstract of the Descriptive Part of a Memoir on the Examination of a Human Ovum of the probable age of 13 to 14 days. In the odontological section Mr. Arthur H. Evans contributes a case of Diffuse Fibromata of the Gums. The otological section includes cases and specimens recorded by Dr. P. McBride, Dr. A. Logan Turner, Mr. H. Wade, Dr. W. Permewan, Dr. J. M. Darling, and others, whilst the surgical section is concerned with an account of the reduction of an old subcoracoid dislocation of the humerus by excavating the glenoid cavity through a posterior intermuscular incision by Mr. W. G. Spencer; notes on cases of Cystic Tumour of the Suprarenal Body, including one recorded by Greiselius of Vienna in 1670, by Mr. A. H. G. Doran; and two difficult cases of fracture by Mr. Rushton Parker.

\section{MEDICINE AND THE LAW.}

\section{"Dairying" in a Stable.}

THE health authorities at Hastings are to be congratulated upon being successful in not only putting an end to a serious fraud that was being perpetrated upon the inhabitants of that town, but in bringing before the justices the perpetrators after they had only been operating for a space of three weeks. Two men, George Cooper and Henry Dagnell, between August 13th and Sept. 5th, purchased from retail premises at Hastings no fewer than 654 pounds of margarine in small quantities at a time. They took their purchases to a stable which they had hired and here they made the margarine up into half-pound pats (with scales which were three-quarters of an ounce against the purchaser), afterwards hawking it round the town as genuine "Devonshire" butter. Their story was that they had just come from the country with the "butter" and their general attire was quite consistent with this statement. But purchases came to be made for the purpose of analysis, and the result was that the so-called "Devonshire butter" was found to be nothing more nor less than margarine. A warrant was secured for the arrest of the two men, and within a very few hours both men were sentenced to three months' hard labour without the option of a fine for obtaining money by false pretences. It is such sentences as these that are needed in cases of gross fraud where foodstuffs are concerned, and the justices, no doubt, were influenced by the aggravating circumstances in the case. The margarine was kept and "prepared" for sale in a stable which was actually being used as such, a pony being in the stall and manure lying about the floor at the time of the inspector's visit. To have proceeded against these men by summons would probably have resulted in them not being found, the pony and cart at the stable being quite capable of carrying them and their "dairying" utensils on to some other town where the same nefarious business might be carried on, and, perhaps, for a longer period than at Hastings.

\section{Reform in Expert Medical Evidence. ${ }^{1}$}

The Massachusetts Medical Society is endeavouring to procure legislation to bring about a change in the present conditions of medical expert testimony in the United States. Apart from the possible combination of unworthy lawyers and unworthy medical men, examples of which have been furnished in America, there is often witnessed the sorry spectacle of honest and reputable physicians arrayed on opposite sides in a law court and made to appear to give sworn opinions in quite conflicting manners concerning subjects upon which but one view would exist were the proceedings conducted by a private consultation among the witnesses. A distinguished judge in Massachusetts is reported to have observed lately: "If there is any kind of testimony that is not only of no value, but even worse than that, it is in my judgment that of the medical expert." To ameliorate this state of affairs it is suggested to enact that the court may on its own motion and at the request of either of the contending parties appoint one or more medical witnesses of approved training and experience to give expert testimony on any case under consideration. The Bill suggested proposes that such a report shall be considered legally as similar to that given to the report of an auditor. In furtherance of this plan it is proposed that the leading medical societies should furnish the Chief Justice of the Supreme Court with a panel of 50 medical men of high professional standing from whom may be selected expert witnesses with the designation of the specialty in which each is deemed to be an authority. Reasonable compensation for services so rendered are to be allowed by the court and paid from the county funds. The appointment of these official witnesses by the court is not to preclude the testimony of other skilled witnesses who may be called privately. The passage of such a measure by the legislature would revolutionise the present undesirable conditions under which expert evidence is produced; the medical expert would then be what his designation implies and would cease from being merely a medical advocate. The Bill is said to have the cordial endorsement of the best element of the legal and medical professions in the State of Massachusetts.

1 A motion for reform carried by medical men in Boston was reported in The LaNCET of June 6th, 1908, p. 1651.

\title{
能efor a duturentions.
}

\section{A NASAL SNARE.}

THIs snare has been made for me by Messrs. Mayer and Meltzer, 71, Great Portland-street,

London, W. The chief feature is the ease and rapidity with which the end can be threaded with wire. The point of the snare is small and rounded, so that the wire retains its loop and can be used for many polypi. The central od is drawn straight back instead of over an angle as in some other forms. The snare is light and strong and has been proved efficient by everyday use in hospital. 


\section{THE LANCET.}

LONDON: SATURDAY, SEPTEMBER 19, 1908.

\section{The Sixty-Second Report of the Commissioners in Lunacy.}

THE statistics contained in this report are not materially different from similar statistics of the last few years and there is a continued increase in the number of insane persons known to be under care. The number of such persons on Jan. 1st, 1907, was 123,988 and on Jan. 1st, 1908, was 126,084, being an increase of 2096. As, however, the annual average increase for the ten years ending with 1907 was 2411 the increase for 1907 was less by 315 than the annual average of the decennium. It was found that the- ratio of notified insane persons to the estimated population was on Jan. 1st, 1908, 1 to 280 , or 35.67 per 10,000 . This is an increase on the ratio of the year before of 0.53 per cent. and an actual numerical increase of nearly 1.7 per cent. At the beginning of 1898 the ratio of insane persons to the estimated population was $32 \cdot 35$, so that since then it has increased by as much as 10.2 per cent., the proportion of insane persons having risen from 1 in 309 to 1 in 280 . The increase in the whole population has been $12 \cdot 2$ per cent., while in the number of the insane it has been 23.7 per cent. Examining the ratio for a larger number of years we find that while the estimated population increased by $57 \cdot 2$ per cent. between the years 1869 and 1907 the total number of the known insane increased by $137 \cdot 1$ per cent. The ratio of the insane to the population was at the beginning of 1869 23.93 per 10,000 and on Jan. 1st of this present year 35.67 per 10,000 , being an increase of 49 per cent. The ratios for first admissions were $4 \cdot 92$ per 10,000 in $1898,5 \cdot 76$ in $1902,5 \cdot 16$ in 1906 , and $5 \cdot 18$ in 1907 . The number of patients at the beginning of 1907, not counting those in idiot establishments, in institutions, and in single private care, was 98,521 , being an increase of 32 per cent. on the number under similar care at the beginning of 1897. During these ten years the numbers in county and borough asylums had increased by $36 \cdot 6$ per cent., in registered hospitals by 3.6 per cent., in the State asylums by 26.4 per cent., and in single care by $17 \cdot 3$ per cent.

It appears that nearly three-fourths of the number of patients annually certified are suffering from their first attack, while the remainder represent recurrent cases. The report points out that it is highly probable that, at any rate among certain classes, the too speedy return to old arocations and the environment under which the patient originally broke down contributes to the recurrence of the malady. It may be that at some future date it will be more widely recognised to be desirable that the patient should be subjected to a more careful supervision on his discharge from the asylum. To this end it may be found necessary to establish convalescent homes where the recovery of patients may be still further insured. The After-Care Association, unfortunately only in a very small way, undertakes at the present time to do what it can for discharged patients and deserves far more support from the public than it receives. It is quite possible that a considerable extension of this work might contribute in no small degree to a decrease in the amount of insanity in this country.

We are happy to note that the Commissioners are very decidedly of opinion that the asylums should be utilised to further the scientific study of insanity and higher medical education. Too often the asylum is regarded rather as a place of detention where persons who are a nuisance to the community are confined, instead of a place of refuge for the sufferer where he may obtain appropriate treatment for his disease. We cannot, however, but feel that there are indications that the public are beginning to regard insanity as a disease which is to be studied and treated in precisely the same way as are those diseases in which disordered function is more obviously the result of organic alteration of the tissues. A substantial part of this excellent change in public opinion must be attributed to the earnest scientific labours of those working in this branch of our science and art, their labours involving investigations in the phenomena of mind and in the structure and function of its delicate instrument and constant servant, the brain. But perhaps a yet larger factor in the production of this change has been the work of the Commission in Lunacy. From a disorderly and sometimes disgraceful chaqs there has been evolved under its guidance a systematisation of philanthropic effort for the amelioration of the condition of the insane. The work of the Commission is now of such extent that it cannot be efficiently performed by the present number of the Commissioners. That the best that can be done is being done there can be no doubt from a perusal of the report now before us. But times have changed and the large increase of the insane population demands a larger Commission and one in which less prominence shall be given to what we may call its police functions and more to the more strictly medical aspects of the work. We trust that the adoption of some of the recommendations of the Royal Commission on the Feeble-Minded ${ }^{1}$ may eventuate in such an improvement.

\section{Huntington's Chorea or Chronic Progressive Chorea.}

ThIRTY-SIX years ago Dr. George Huntington, then a recently qualified practitioner of but 22 years of age, at the end of a paper on the subject of chorea in childhood, gave a description in a few strikingly graphic sentences of that peculiar form of chorea which has since that time been generally called after him, a description so complete and so distinctive that from a clinical standpoint little or nothing has since been added. It is always interesting, stimulating, and instructive to study the history of any scientific advance and to trace the evolution of knowledge in regard to it. We have received an interesting pamphlet ${ }^{2}$ which, though of modest dimensions and of unpretentious character, is a very York : Albert T. Huntington. 1908. 